\title{
Functional Mapping of the Auditory Midbrain during Mate Call Reception
}

\author{
Kim L. Hoke, ${ }^{1}$ Sabrina S. Burmeister, ${ }^{3}$ Russell D. Fernald, ${ }^{4}$ A. Stanley Rand, ${ }^{5}$ Michael J. Ryan, ${ }^{1}$ and Walter Wilczynski ${ }^{2}$ \\ ${ }^{1}$ Section of Integrative Biology and ${ }^{2}$ Department of Psychology, University of Texas at Austin, Austin, Texas 78712, ${ }^{3}$ Department of Psychology and \\ ${ }^{4}$ Neurosciences Program, Stanford University, Stanford, California 94305, and ${ }^{5}$ Smithsonian Tropical Research Institute, Balboa, Panama
}

\begin{abstract}
We examined patterns of neural activity as assayed by changes in gene expression to localize representation of acoustic mating signals in the auditory midbrain of frogs. We exposed wild-caught male Physalaemus pustulosus to conspecific mating calls that vary in their behavioral salience, nonsalient mating calls, or no sound. We measured expression of the immediate early gene egr-1 (also called ZENK, zif268, NGFI-A, and krox-24) throughout the torus semicircularis, the auditory midbrain homolog of the inferior colliculus. Differential egr-1 induction in response to the acoustic stimuli occurred in the laminar, midline, and principal nuclei of the torus semicircularis, whereas the ventral region did not show significant effects of stimulus. The laminar nucleus differentially responded to conspecific mating calls compared with nonsalient mating calls, whereas the midline and principal nuclei responded preferentially to one of two conspecific calls. These responses were not explained by simple acoustic properties of the stimuli, and they demonstrate a functional heterogeneity of auditory processing of complex biological signals within the frog midbrain. Moreover, using analyses that assess the ability of the torus semicircularis as a whole to discriminate among acoustic stimuli, we found that activity patterns in the four regions together provide more information about biologically relevant acoustic stimuli than activity in any single region.
\end{abstract}

Key words: auditory; midbrain; amphibian; egr-1; mating; túngara frogs

\section{Introduction}

Socially modulated behavioral decisions, such as the amount of energy to invest in mating displays, require accurate representation of complex social cues in the brain. Here, we investigate the representation of acoustic communication signals that vary in their behavioral salience.

The frog auditory system is a classic model for the study of neural processing of communication signals. The torus semicircularis (torus), an amphibian midbrain auditory center homologous with the mammalian inferior colliculus, has several divisions that differ in cytoarchitecture, chemoarchitecture, and connections (Potter, 1965; Wilczynski, 1981, 1988; Fuzessery, 1988; Endepols et al., 2000). The principal nucleus neurons are the major toral target of brainstem auditory regions and provide a significant source of ascending auditory connections to thalamic nuclei (Rubinson and Skiles, 1975; Feng, 1986a,b; Hall and Feng, 1987; Feng and Lin, 1991). The ventral area is a cell-sparse zone that contains the neuropil of principal nucleus neurons, numerous multipolar neurons, and magnocellular cells with wide-ranging projections (Feng, 1983; Wilczynski, 1988). It is often included as part of the principal nucleus (excluding the caudolateral magnocellular cells). Laminar nucleus neurons re-

Received May 28, 2004; revised Nov. 3, 2004; accepted Nov. 4, 2004.

The Smithsonian Tropical Research Institute, National Science Foundation, and National Institutes of Health provided generous funding for this research. We thank Ximena Bernal, Jennifer Gench, Kathleen Lynch, and Kathrin Lampert for assistance with experiments. We thank Erich Jarvis for procedural advice.

Correspondence should be addressed to Kim Hoke, Section of Integrative Biology, 1 University Station C0930, University of Texas at Austin, Austin, TX 78712.

D01:10.1523/JNEUROSCI.2079-04.2004

Copyright $\odot 2004$ Society for Neuroscience ～0270-6474/04/2411264-09\$15.00/0 ceive ascending auditory inputs and descending inputs from forebrain areas and are the major source of auditory connections to thalamic and brainstem areas (Wilczynski and Northcutt, 1983; Feng, 1986b; Feng and Lin, 1991; Marin et al., 1997; Luksch and Walkowiak, 1998; Endepols and Walkowiak, 2001). Potter (1965) also described two midline regions on cytoarchitectonic grounds. None of these regions are clearly equivalent to specific mammalian inferior colliculus subdivisions, although they share similar connections (Wilczynski and Capranica, 1984; Wilczynski, 1988).

Electrophysiological studies have identified toral neurons with complex feature detection properties that presumably contribute to the representation of mating calls (Rose and Capranica, 1984; Walkowiak, 1984, 1988; Wilczynski and Capranica, 1984; Diekamp and Schneider, 1988; Fuzessery, 1988; Feng at el., 1990; Penna et al., 1997; Edwards et al., 2002). Moreover, different features of acoustic signals are processed in separate streams in the auditory system. For example, different neurons within the torus show spectral and temporal selectivity (Diekamp and Schneider, 1988; Fuzessery, 1988; Walkowiak, 1988; Penna et al., 1997). Whereas the physical arrangement of toral frequencyoriented and timing-oriented neurons is unknown (Walkowiak and Luksch, 1994), those functions are segregated into two different thalamic nuclei that receive toral projections (Hall and Feng, 1987). To assess the function of toral subdivisions in analyzing communication sounds, we used expression of the immediate early gene egr-1 as an indicator of neural activity. We compared mean egr-1 expression in each toral region after presentation of conspecific, heterospecific, or no mating calls. In addition, based on the prediction that different aspects of mating 
calls could be processed in different toral regions, we performed a discriminant function analysis to determine whether the pattern of neural activity across the entire torus better distinguished stimuli than activity in individual regions.

\section{Materials and Methods}

We chose egr-1 quantification as our measure of neural activity based on its previous effectiveness in measuring auditory biases for acoustic communication signals (Mello et al., 1992; Gentner et al., 2001; Sockman et al., 2002; Maney et al., 2003). Neuronal egr-1 expression is regulated by synaptic activity (Worley et al., 1991) and is linked to membrane depolarization through multiple second messenger cascades (Murphy et al., 1991; Whitmarsh et al., 1995; Treisman, 1996; Harada et al., 2001; Sweatt, 2001; Bozon et al., 2003; Buchwalter et al., 2004; Cheng and Clayton, 2004). Because egr-1 mRNA levels typically peak 20-30 min after stimulation (for review see Clayton, 2000; Burmeister and Fernald, 2005), one can infer a connection between elevated egr-1 expression and recent increases in synaptic transmission; thus, egr-1 expression can be used to map functional activity of brain regions (Jarvis, 2004). Because egr-1 levels integrate neurotransmitter stimulation over tens of minutes, finescaled temporal information is not available. These temporal limitations, along with the difficulty of within-subject designs, are counterbalanced by both a higher threshold for activation than other activity measures (Clayton, 2000) as well as the opportunity to simultaneously measure activity throughout the animal's brain.

Identification of egr-1 cDNA sequence. We used brain tissue of Physalaemus pustulosus from a laboratory stock originally derived from natural populations in Gamboa, Panama. We isolated total RNA from brain homogenates (Ultraspec-II; Biotecx Laboratories, Houston, TX) and synthesized cDNA using an anchored poly-dT primer and Superscript II Reverse Transcriptase (Invitrogen, Carlsbad, CA). We used Codehop (http://blocks.fhcrc.org/blocks/codehop.html) to design the following degenerate primers: forward, $5^{\prime}$-CCT TCC AGG TGC CCA TGA THC CNG A -3'; reverse 5'-GGT CGG ACC GGG AGA ART TNC KCA T-3'. To amplify the $411 \mathrm{bp}$ fragment, we used Klentaq1 DNA polymerase (AB Peptides, St. Louis, MO) prebound with TaqStart Antibody (Clontech, Palo Alto, CA), a magnesium concentration of $3 \mathrm{~mm}$, primers at $0.5 \mu \mathrm{M}$ each, and the following PCR program on a capillary tube Rapidcycler (Idaho Technologies, Idaho Falls, ID) (note that the rapid heat transfer in a capillary tube thermal cycler does not require hold times for denaturing or annealing steps): an initial $2 \mathrm{~min}$ step at $94^{\circ} \mathrm{C}$ followed by 40 cycles as follows: denaturing for $0 \mathrm{sec}$ at $94^{\circ} \mathrm{C}$, annealing for $0 \mathrm{sec}$ at $55^{\circ} \mathrm{C}, 54^{\circ} \mathrm{C}$, $53^{\circ} \mathrm{C}, 52^{\circ} \mathrm{C}, 51^{\circ} \mathrm{C}$ (three cycles at each temperature), or $50^{\circ} \mathrm{C}(25$ cycles), and extension for $30 \mathrm{sec}$ at $72^{\circ} \mathrm{C}$, concluding with a final extension for 3 min at $72^{\circ} \mathrm{C}$. The amplified band was purified (QIAquick; Qiagen, Valencia CA), cloned (pCR-II-Topo; Invitrogen), commercially sequenced (Biotech Core, Mountain View, CA), and submitted to GenBank (accession number AY562993). To make the in situ hybridization probe, we used a 309 bp clone corresponding to nucleotides 1.309 of the $411 \mathrm{bp}$ clone.

Exposure of frogs to acoustic stimuli. A large body of work has documented the behavioral responses of male and female P. pustulosus to variation in conspecific calls as well as their recognition of conspecific versus heterospecific calls. The simple mating call of males (females do not call), called a whine, consists of a frequency sweep of $\sim 300 \mathrm{msec}$ (Rand and Ryan, 1981). Males also produce a complex mating call, called a whine-chuck, when they append one to six short ( $\sim 40 \mathrm{msec})$ harmonic bursts of sounds, called chucks, onto the whine (Rand and Ryan, 1981). Chucks are never produced alone. P. pustulosus males produce no other call types except a low-amplitude, infrequently used aggressive call (Ryan, 1985). Males increase call complexity in response to the vocalizations of other conspecific males, and females prefer whine-chucks to whines in paired stimulus presentations (Rand and Ryan, 1981). Both males and females will respond behaviorally to a whine or a whine-chuck, but their responses are greater to the whine-chuck, indicating a greater behavioral salience of the whine-chuck (Rand and Ryan, 1981; Ryan, 1985). In this study we contrast responses to these two natural conspecific calls with responses to two sounds that are not naturally occurring in
Panama and induce little or no behavioral response: one heterospecific whine and the chuck component of the natural whine-chuck. Neither sex responds to allopatric P. enesefae whines (Ryan and Rand, 1993) (X. Bernal, A. S. Rand, and M. J. Ryan, unpublished observations). Frogs never produce chucks without whines, and males call in response to artificially synthesized chucks less than to whines (Ryan, 1985).

Autoridad Nacional del Ambiente del República de Panamá approved the collection, animal protocols, and exportation of tissue (permit number SEX/A 072-02). Calling males were captured between 7:30 and 11:30 P.M. between July 21 and August 16, 2002 from natural breeding aggregations near facilities of the Smithsonian Tropical Research Institute in Gamboa, Panama. Once in the laboratory, individual males were placed in small plastic bags with $\sim 200 \mathrm{ml}$ water, and housed in sound attenuation boxes in a room without air conditioning (ambient temperature averaged $26^{\circ} \mathrm{C}$ ). Previous studies have shown that these plastic bags are acoustically transparent to the stimuli used in this study (Ryan and Rand, 1998). During the day the doors of the sound attenuation boxes were opened to allow the males to experience a natural diurnal light cycle available through windows in the laboratory.

Males remained in the sound attenuation boxes until experiments were conducted $1 \mathrm{~d}$ after collection. To minimize background acoustic stimulation, the boxes were sealed for 2-6 hr (beginning between 6:00 and 7:30 P.M.) before experimental treatment, and males were maintained in darkness with no sound presentation. During that time, male calling was monitored through a sound pressure level meter (Radio Shack, Fort Worth, TX), and spontaneously calling males were excluded from the experiment. Males were exposed to acoustic stimuli broadcast one call every $2 \mathrm{sec}$ through a CD player and a loudspeaker for $15 \mathrm{~min}$. Frogs were placed $\sim 20 \mathrm{~cm}$ from the loudspeaker, a distance calibrated for a sound pressure level of $82 \mathrm{~dB}$ SPL (re. $20 \mu \mathrm{P}$ ).

Animals were assigned at random to one of five acoustic treatments (Fig. 1): no sound $(n=7)$, natural $P$. enesefae whine $(n=7)$, natural $P$. pustulosus whine $(n=12)$, natural $P$. pustulosus whine with three chucks ( $n=10)$, or three chucks excised from the natural P. pustulosus whinechuck $(n=9)$. All stimuli were partial or complete recordings of natural calls. Both $P$. enesefae and $P$. pustulosus whines are downward frequency sweeps with maximal energy $<1 \mathrm{kHz}, P$. enesefae of $700 \mathrm{msec}$ duration, and $P$. pustulosus of $300 \mathrm{msec}$. The whine-chuck stimulus includes a $P$. pustulosus whine with the addition of three chucks, broadband harmonic bursts with energy concentrated in harmonics of $\sim 2.5 \mathrm{kHz}$. The chuck stimulus includes only the chucks from the whine-chuck stimulus. All acoustic stimuli were scaled to the same maximal peak-to-peak amplitude, that matching the amplitude of frogs calling under natural conditions 0.5 m away (Ryan and Rand, 1990).

Some animals called during stimulus presentation, whereas others remained silent. All calling responses were recorded (lapel microphone, Radio Shack; PMD 420 tape recorder, Marantz). After stimulation, males were kept for $15 \mathrm{~min}$ without hearing sounds before decapitation. Eyes and skin were quickly trimmed, and remaining heads were flash frozen in liquid nitrogen in $2 \mathrm{ml}$ tubes containing Tissue-Tek OCT Compound (Sakura Finetek, Torrance, CA).

Detection of egr-1 mRNA. Flash-frozen heads were stored in liquid nitrogen for up to 1 month before being transported to The University of Texas at Austin and transferred to a $-80^{\circ} \mathrm{C}$ freezer until sectioning. Brains were sectioned on a cryostat (Reichert-Jung 2800 Frigocut E) at 16 $\mu \mathrm{m}$ thickness and mounted onto Superfrost Plus slides (Fisher Scientific, Santa Clara, CA). Slides were stored at $-80^{\circ} \mathrm{C}$ before in situ hybridization.

S-35 labeled RNA probes were prepared for egr-1 detection. Plasmid containing egr- 1 was linearized by digestion with EcoRV (antisense; Invitrogen) or BamHI (sense; Invitrogen) and purified using GENECLEAN (Qbiogene, Vista, CA). Linearized plasmid concentration was determined by comparison with high DNA mass ladder (Invitrogen) after gel electrophoresis. S-35-labeled RNA was transcribed by T7 (antisense) or SP6 (sense) polymerase using a MAXISCRIPT kit (Ambion, Austin, TX). Unincorporated nucleotides were separated in NucAway spin columns (Ambion). Probe quality was verified by gel electrophoresis, and probe quantity was determined by scintillation counter.

All slides of $P$. pustulosus male brain sections were simultaneously processed for egr-1 in situ hybridization in one batch. Slides were thawed 

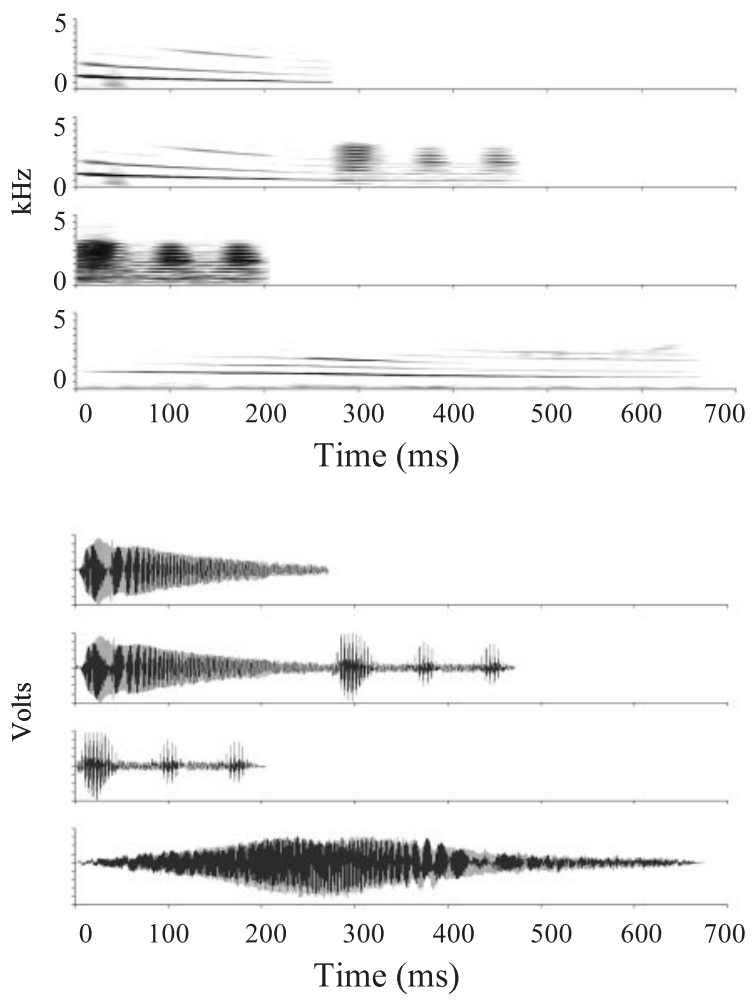

Figure 1. Acoustic stimuli presented to frogs. Sonograms (top graphs) and waveforms (bottom graphs) of treatment stimuli (top to bottom): conspecific $P$. pustulosus whine (whine), conspecific whine plus three chucks (whine-chuck), three chucks (chuck), and heterospecific whine ( $P$. enesefae). Peak-to-peak amplitudes of stimuli were matched. Total call energy relative to $P$. pustulosus whine: whine chuck $1.36 \mathrm{~dB}$, P. enesefae $7.82 \mathrm{~dB}$, and chuck, $-15.4 \mathrm{~dB}$.

and fixed for $2.5 \mathrm{~min}$ in $4 \%$ formaldehyde (diluted from $37 \%$ formaldehyde ampules; Ted Pella, Redding, CA) in $1 \times$ PBS (Ambion). Slides were rinsed in water and then $0.1 \mathrm{M}$ triethanolamine (TEA; Sigma, St. Louis, $\mathrm{MO})$. Tissue charge was neutralized using $0.05 \%$ acetic anhydride (Sigma) in $0.1 \mathrm{~m}$ TEA for $10 \mathrm{~min}$. Slides were transferred to $2 \times$ SSC (Ambion) then dehydrated in 50, 75, 95, and 100\% ethanol (3 min each). Tissue was rehydrated in radiolabeled riboprobe $\left[2.5 \times 10^{5} \mathrm{cpm} / \mathrm{ml}\right.$ diluted in $1 \times$ hybridization solution (Sigma) with $0.01 \mathrm{~m}$ dithiothreitol (Sigma)], sealed with cover glasses, and hybridized for $16 \mathrm{hr}$ in a mineral oil bath at $65^{\circ} \mathrm{C}$. After hybridization, oil was removed by two chloroform rinses and two $2 \times$ SSC rinses. Slides were washed at $65^{\circ} \mathrm{C}$ to remove nonspecific probe binding as follows: $1.25 \mathrm{hr}$ in $2 \times$ SSC and $50 \%$ formamide (Sigma) followed by two washes for $30 \mathrm{~min}$ each in $0.1 \times$ SSC. Slides were then dehydrated in increasing ethanol concentrations.

To visualize radiolabeled egr-1, slides were processed for autoradiography. Slides were immersed in xylenes for $10 \mathrm{~min}$ then rinsed in ethanol and dried. Slides were dipped in $37^{\circ} \mathrm{C}$ Kodak NTB2 emulsion (VWR Scientific, Brisbane, CA) and dried at $50^{\circ} \mathrm{C}$ for four hours. Slides were wrapped in lightproof boxes and stored at $4^{\circ} \mathrm{C}$ for $14 \mathrm{~d}$. Emulsion was developed using D19 developer (VWR Scientific) and Kodak Fixer (VWR Scientific), then tissue was stained in cresyl violet to facilitate identification of toral nucleus boundaries, and slides were coverslipped in Permount (Fisher Scientific).

The torus semicircularis showed strong egr-1 expression in antisense slides (Fig. 2). Silver grain density in the brain sections hybridized with the sense probe did not differ from background silver grain density (data not shown). The optic tectum, a region that processes visual information and is adjacent to the torus in each section, did not show egr-1 levels above background (Fig. $2 \mathrm{~A}$ ), as one would predict for males deprived of visual information. Thus, we conclude that silver grain precipitation was specifically localized where egr-1 mRNA was expressed.

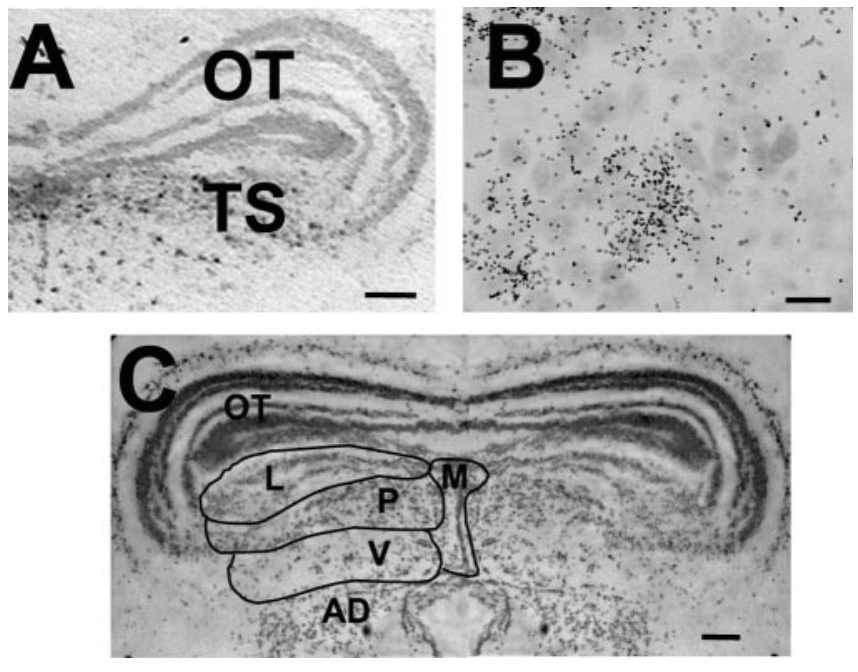

Figure 2. Photomicrographs showing typical cytoarchitecture and egr-1 expression within the torus semicircularis of animals hearing acoustic stimuli. A, Sections hybridized with the antisense probe showed high egr- 1 expression in the torus semicircularis (TS) but little expression within the optic tectum (OT). Scale bar, $0.1 \mathrm{~mm}$. B, An example of a photograph used for quantitative analysis. Black spots were counted to determine number of silver grains within the field of view, and cell bodies were measured to determine area of frame covered by cells. All images for quantification were photographed at this magnification. Scale bar, $0.01 \mathrm{~mm}$. C, Section stained with cresyl violet to show toral subdivisions. Left half of panel is mirror image of photograph on right half for clarity. Laminar nucleus (L) cells formed layers oriented mediolaterally extending from the ventrolateral edge of the optic tectum (OT). Principal nucleus ( $P$ ) cells were densely packed below the laminar nucleus layers. The midline nucleus included the cells clustered along the dorsoventral extent of the midline. The ventral region $(\mathrm{V})$ included the sparse cells between the principal nucleus and anterodorsal tegmentum (AD). Scale bar, $0.1 \mathrm{~mm}$.

Quantitative analysis of egr-1 expression. Relative expression of egr-1 was assessed by silver grain density measurements in the laminar, principal, and midline nuclei and cell-sparse ventral area of the torus semicircularis (see Fig. $2 C$ for subdivision boundaries). Although large cells were scattered within the lateral ventral area, we could not clearly distinguish a separate magnocellular nucleus in this species on cytoarchitectonic grounds, and therefore could not analyze it as a separate nucleus. For each subdivision, we calculated an individual's mean silver grain density from multiple digital images taken with a $100 \times$ objective from multiple brain sections using systematic random sampling. Images were chosen for analysis based on cresyl violet label using landmarks within the torus semicircularis that change across the rostrocaudal extent, and analyzed sections were separated by at least $32 \mu \mathrm{m}$.

For the laminar nucleus, we calculated an individual's mean from up to nine images taken as three nonoverlapping images from each of three sections. The laminar images from one section were taken at $250 \mu \mathrm{m}$ intervals beginning near the lateral border of the nucleus with the optic tectum and proceeding medially along the dorsal border of the nucleus. For the principal nucleus, we calculated an individual's mean from up to 12 images taken as three nonoverlapping images from each of four sections. The principal nucleus images from one section began laterally near the optic tectum border and proceeded in $250 \mu \mathrm{m}$ intervals along a line bisecting the nucleus from the lateral point to the midline. For the midline region, we calculated an individual's mean from up to six images taken as three nonoverlapping images from each of the two rostral sections. Midline photographs from one section were spaced by $100 \mu \mathrm{m}$ and proceeded ventrally along the cell-dense midline region [similar to the subependymal midline nucleus described by Potter (1965), but in $P$. pustulosus the cell-dense portion of the midline extends more ventrally than in Rana catesbeiana]. We distinguished a separate ventral region [which corresponds to the magnocellular nucleus and ventral part of the principal nucleus in Feng (1983) and Endepols et al. (2000)] (see Wilczynski, 1988) on the basis of its cell density being much less than the overlying part of the principal nucleus, and calculated an individual's 
Table 1. Egr-1 expression in torus semicircularis of animals in all acoustic treatments

\begin{tabular}{|c|c|c|c|c|c|c|c|c|}
\hline & \multicolumn{2}{|c|}{ Laminar egr-1 levels } & \multicolumn{2}{|c|}{ Midline egr- 1 levels } & \multicolumn{2}{|c|}{ Principal egr-1 levels } & \multicolumn{2}{|c|}{ Ventral egr-1 levels } \\
\hline & Mean $\pm S E$ & $n$ & Mean \pm SE & $n$ & Mean \pm SE & $n$ & Mean $\pm S E$ & $n$ \\
\hline No sound & $1.72 \pm 0.44$ & 7 & $2.70 \pm 0.85$ & 6 & $3.23 \pm 0.90$ & 7 & $0.88 \pm 0.22$ & 7 \\
\hline P. enesefae & $2.04 \pm 0.34$ & 7 & $4.50 \pm 0.69$ & 7 & $3.88 \pm 0.25$ & 7 & $0.96 \pm 0.18$ & 7 \\
\hline Chuck & $2.37 \pm 0.54$ & 9 & $5.03 \pm 0.94$ & 9 & $4.71 \pm 0.80$ & 9 & $1.75 \pm 0.35$ & 9 \\
\hline Whine & $3.01 \pm 0.31$ & 12 & $6.35 \pm 0.78$ & 12 & $5.36 \pm 0.50$ & 12 & $2.35 \pm 0.67$ & 12 \\
\hline Whine-chuck & $3.57 \pm 0.46$ & 10 & $4.02 \pm 0.74$ & 10 & $3.87 \pm 0.52$ & 10 & $1.64 \pm 0.37$ & 10 \\
\hline
\end{tabular}

mean from up to six images taken as three nonoverlapping images from each of two central sections. For an individual section, images within the ventral region were separated by $100 \mu \mathrm{m}$ in a lateral to medial direction. Sections that were torn, missing, or angled were excluded from the analysis, and the final image in a section was excluded if the third photo in the series fell outside the region being analyzed. For each section analyzed we also took images near the tissue over a blank area of the slide to calculate local background silver grain density.

Egr-1 expression levels in all photographs were quantified using custom automated counting procedures. Bright-field images were duplicated in Adobe Photoshop 7 and processed to separate from the rest of the image either cresyl-violet stained cell bodies or silver grains within the regions covered by cell bodies. Cell bodies were isolated using "select color" function, thresholds were set individually for each image, and the remainder of the image was erased. Silver grains were isolated in the duplicate image by first selecting the regions covered by cells, then using select color to isolate in-focus silver grains within those cell-covered regions, and finally erasing the remainder of the image. Area covered by cell bodies and grain number within a standard-sized sampling frame were determined using NIH ImageJ. Silver grain density within the frame, our estimate of egr-1 expression level, was calculated as the ratio of silver grain counts to pixels covered by cells. The local baseline silver grain density was estimated from images of silver grains off the tissue beside each section and subtracted from each egr-1 measurement.

Statistics. All statistical analyses were performed using SPSS 11 .

Since this is the first report of egr-1 expression in the frog auditory system, we examined whether egr-1 expression, in general, differed among toral subdivisions. To do so, we used repeated measure ANOVA with brain region (laminar, midline, principal, and ventral nuclei) as the within-subject factor; we included all 44 frogs that had egr-1 expression measurements for all four toral regions. We did not include any betweensubject factors in this analysis. Pairwise comparisons were based on estimated marginal means with Bonferroni correction. We also tested for covariation among subdivisions using two-tailed pairwise Pearson correlation coefficient.

Because the act of calling changes the acoustic environment, we tested whether calling influenced egr-1 levels for each subdivision. The analysis of each subdivision included 6-12 animals per treatment for a total of 44-45 animals (Table 1). We used a two-factor univariate ANOVA to determine the main effects of acoustic stimulus and calling as well as the call-by-stimulus interaction on mean egr-1 levels in each toral region. Because no animals in the unstimulated group called, we used type IV Sum of Squares for all ANOVA effects. We used discriminant function analysis (DFA) to test whether, when considered simultaneously, the four subdivisions differed between males that called and those that did not for males that heard one of the four mating call stimuli. We also assessed potential covariance between the total amount of calling (number of calls produced) and egr-1 expression in the torus using two-tailed pairwise Pearson correlation coefficient.

To determine how the acoustic stimuli influenced egr-1 expression in the torus, we used the two-factor ANOVA for call and stimulus described above and further analyzed the specific effects of acoustic stimulus using three orthogonal contrasts as follows. To test for the effect of sound, we compared males that heard any mating call to those that heard no sound (sound vs no sound). To test for the effect of natural conspecific calls, we compared males that heard the whine or whine-chuck to males that heard the chuck alone or P. enesefae whine (salient vs nonsalient). To test for the effect of the two natural conspecific calls with distinct behavioral preferences, we compared males that heard the whine to those that heard the whine-chuck (whine vs whine-chuck).

We chose our stimuli to represent particular categories of mating calls or call components. However, the stimuli can also be represented by continuous variables of their acoustic parameters (call duration, total energy, peak frequency, maximum amplitude), and the auditory system may very well be responding to particular parameters rather than call categories. To determine if individual acoustic parameters of the stimuli covaried with egr-1 expression of toral subdivisions, we used two-tailed pairwise Pearson correlation coefficient. For example, total energy for each of the four acoustic stimuli was compared with laminar nucleus egr-1 levels averaged over the 7-12 animals in each stimulus group.

The above analyses examined the effects of acoustic stimulation on each toral subdivision separately. We also addressed whether the acoustic stimuli influenced the pattern of egr-1 expression across the four subdivisions. To do so, we used a DFA, which tests the ability of egr-1 expression patterns to classify individual males by which stimuli they experienced. The DFA used the mean egr- 1 levels of the four toral subdivisions as independent variables and mating call stimulus heard (whine, whinechuck, chuck, or heterospecific whine) as grouping variable. All groups had equal prior probability and independents were entered together. DFA generates orthogonal discriminant functions that are linear combinations of the independent variables used to classify cases of the grouping variable. The statistical significance of the DFA was assessed by calculating Wilks' lambda, and the $p$ value was estimated by $\chi^{2}$ approximation. To characterize the relative contributions of each independent variable, we evaluated the eigenvalue of each discriminant function, related to the percentage of variance of the grouping variable each function explains, and the standardized canonical discriminant coefficients that represent the contribution of each independent variable to a function. In addition to standard DFA classification, we tested for covariation between the DFA discrimination values and four acoustic parameters (call duration, peak frequency, total energy, and maximum amplitude) using two-tailed pairwise Pearson correlation coefficient. To see whether all four regions classified individuals based on stimulus better than any single toral region, we also conducted four separate DFA analyses with each individual toral region as an independent variable. We compared the DFA including all four toral regions with each DFA including a single toral region using the ratios of the Wilks' lambda (Tabachnick and Fidell, 1983).

\section{Results \\ Regional differences in egr-1 expression in the torus semicircularis}

The torus semicircularis demonstrated substantial spatial heterogeneity in egr-1 expression. The laminar and principal nuclei had within-subdivision variation in egr-1 expression such that egr-1 expression was highest caudally and medially (data not shown). However, this within-subdivision variation was not differentially affected by acoustic stimulus or calling response (data not shown). We found that egr-1 expression, in general, varied among subdivisions (Fig. 3) $\left(F_{(3,40)}=50.55 ; p<0.001\right)$. Midline and principal toral regions were similar in their mean egr-1 expression, and they each showed higher expression than laminar or ventral cells (pairwise comparisons, $p<0.001$ except midline and principal, $p=0.764$ ). All four regions were significantly correlated with one another. Principal and midline regions were most highly correlated $(r=0.767 ; p<0.001 ; n=44)$ followed by midline and laminar regions $(r=0.619 ; p<0.001 ; n=44)$ and laminar and principal nuclei $(r=0.577 ; p<0.001 ; n=45)$. The ventral region was also correlated with other toral nuclei (laminar, $r=0.367, p=0.013, n=45$; midline, $r=0.358, p=0.017$, $n=44$; principal. $r=0.464, p=0.001, n=45$ ). 
Behavior-related differences in toral egr-1 expression

Because vocalization constituted a behavioral difference between subjects as well as a change in their acoustic environment, we tested whether producing calls altered egr-1 expression. We found no significant main effects of calling or call-by-stimulus interactions on egr-1 expression, although call-by-stimulus interactions in the laminar and principal nuclei had significance levels $<0.1$ (Table 2). Combining the egr-1 expression levels in all four toral subdivisions using discriminant function analysis did not distinguish callers from noncallers (Wilks' lambda $=0.978$; $\left.\chi^{2}(4)=0.883 ; p=0.927\right)$.

We also tested whether egr-1 expression varied consistently with the number of calls produced by the calling males. We found no significant correlation between the number of calls produced and egr-1 expression in any subdivision (Table 2), although the midline nucleus showed a slight negative relation between call production and egr-1 levels $(r=-0.489 ; p=0.127 ; n=11)$ whereas the ventral region showed a slight positive relation $(\mathrm{r}=$ $0.454 ; p=0.161 ; n=11$ ). We conclude that calling does not have a consistent effect on egr-1 levels in the torus. It is possible that other brain regions have elevated egr-1 levels after production of mating calls (as found for singing birds, e.g., Mello and Ribeiro, 1998; Jarvis et al., 2000).

\section{Stimulus-related differences in toral egr-1 expression}

The torus semicircularis showed significant stimulus-specific patterns of egr-1 expression that varied among subdivisions. Egr-1 expression in the laminar nucleus was significantly different among stimulus conditions, reflecting a pattern of increasing expression from least biologically salient (no sound) to most biologically salient (whine-chuck) (Fig. 4A, Tables 2, 3) $\left(F_{(4,40)}=3.477 ; p=0.017\right)$. The laminar nucleus showed a strong egr-1 elevation in males hearing biologically salient mating calls (whine and whinechuck) compared with those hearing nonsalient mating call stimuli ( $P$. enesefae whine and chuck alone) $\left(t_{(40)}=2.645 ; p=0.012\right)$.

In the other three toral regions, egr-1 expression showed a similar overall pattern in which the mean response to the whine was greatest. Main effects of egr-1 levels in the midline region were not significantly different based on stimulus condition (Table 2) $\left(F_{(4,39)}=2.145 ; p=0.096\right)$, but frogs exposed to whinechuck had lower egr-1 expression than animals that heard whine only (Fig. $4 B$, Table 3$)\left(t_{(39)}=2.432 ; p=0.02\right)$. The general pattern of egr-1 expression in the principal nucleus was similar (Fig. 4C, Tables 2, 3), with a nonsignificant overall effect of stimulus condition $\left(F_{(4,40)}=1.442 ; p=0.24\right)$, and a greater response to whine than that to the whine-chuck $\left(t_{(40)}=2.053 ; p=0.047\right)$. Egr-1 levels in the ventral nucleus did not differ significantly overall, and none of the contrasts showed differences in egr-1 expression between stimuli (Fig. 4D, Table 3). The mean egr-1 levels for each stimulus condition were not significantly correlated with simple acoustic properties of the calls (call duration, total energy, peak frequency, and maximum amplitude) for any toral subdivision (data not shown).

We considered data from all four regions to determine how well individual stimuli were represented by egr-1 expression levels throughout the torus. Discriminant function analysis showed significant differences among the egr-1 levels for the four different acoustic stimuli (Fig. 5, Table 2) (Wilks' lambda =0.430; $\chi^{2}(12)=27.88 ; p=0.006,68.4 \%$ classified correctly). Individu-

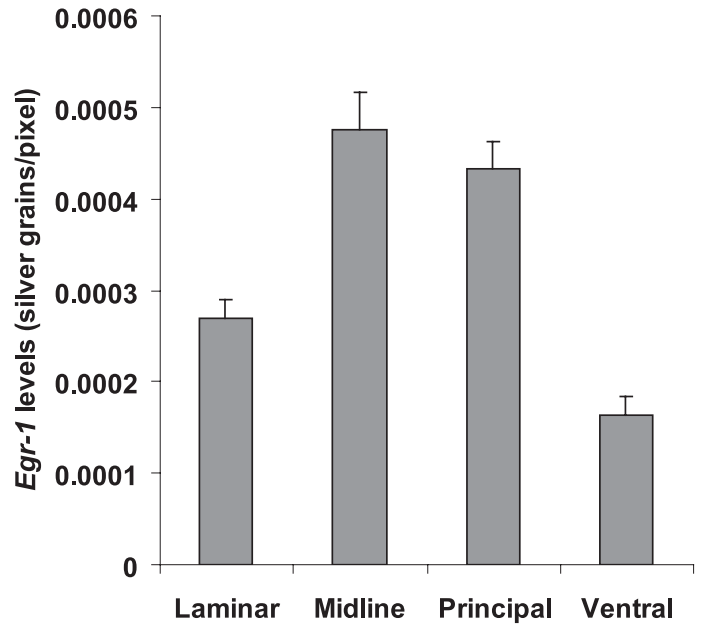

Figure 3. Mean egr-1 expression differs in subdivisions of the toral semicircularis. Mean egr-1 levels in each toral subdivision combining animals in all treatment groups, with error bars indicating SE. Midline and principal regions had the highest egr-1 expression, whereas the ventral nucleus had the lowest expression.
Table 2. Main effects of acoustic stimulus and producing calls on egr-1 expression in toral subdivisions

\begin{tabular}{|c|c|c|c|c|}
\hline & \multicolumn{3}{|c|}{ Two-factor ANOVA call and stimulus } & \multirow{2}{*}{$\begin{array}{l}\text { Correlation with } \\
\text { number of calls }\end{array}$} \\
\hline & Stimulus & Call & Call $\times$ stimulus & \\
\hline Laminar & $F_{(4,30)}=3.477(0.017)$ & $F_{(1,30)}=0.092(0.764)$ & $F_{(3,30)}=2.472(0.077)$ & $r=-0.246(0.466)$ \\
\hline Midline & $F_{(4,30)}=2.145(0.096)$ & $F_{(1,30)}=0.052(0.821)$ & $F_{(3,30)}=1.554(0.218)$ & $r=-0.489(0.127)$ \\
\hline Principal & $F_{(4,30)}=1.442(0.240)$ & $F_{(1,30)}=0.006(0.939)$ & $F_{(3,30)}=2.564(0.070)$ & $r=-0.202(0.552)$ \\
\hline Ventral & $F_{(4,30)}=1.063(0.389)$ & $F_{(1,30)}=0.105(0.748)$ & $F_{(3,30)}=0.405(0.750)$ & $r=0.454(0.161)$ \\
\hline
\end{tabular}

falls

$=-0.246(0.466)$

$r=-0.202(0.552)$

$r=0.454(0.161)$

als that heard whine-chuck and $P$. enesefae whine were classified best (each $>85 \%$ correct) (Table 4 ). Comparing the standardized canonical discriminant coefficients in function 1 , the function that explains $85 \%$ of the variance in the groups of animals that heard the same stimulus, shows that the laminar nucleus was the most important subdivision for discriminating among stimuli (Table 5). The mean canonical discrimination values for each stimulus, like the mean egr-1 levels for each toral region, were not correlated with simple acoustic properties of the calls (call duration, total energy, peak frequency, and maximum amplitude; data not shown).

We also conducted a DFA for each subdivision separately to determine if the accuracy of classification of the four subdivisions combined was greater than that of any single subdivision. This was the case. Even the egr-1 levels of the laminar nucleus, the region that contributed most to stimulus discrimination, were not able to classify the males that heard one of the four mating call stimuli (Wilks' lambda $=0.824 ; \chi^{2}(3)=6.66 ; p=0.84,26.3 \%$ classified correctly). The discrimination with all four toral regions was significantly better than discrimination with laminar nucleus alone $\left(F_{(12,110.4)}=3.534 ; p<0.001\right)$.

\section{Discussion}

The torus semicircularis, a brain region critical for both anuran auditory integration generally and phonotactic responses to mating calls specifically (Endepols et al., 2003), showed differential egr-1 induction in response to biologically relevant acoustic stimuli. Egr-1 activation throughout the torus was not predicted by any single acoustic property of the stimuli. The laminar subdivision, in particular, showed enhanced egr-1 induction in response to both conspecific mating calls. The response pattern of the 

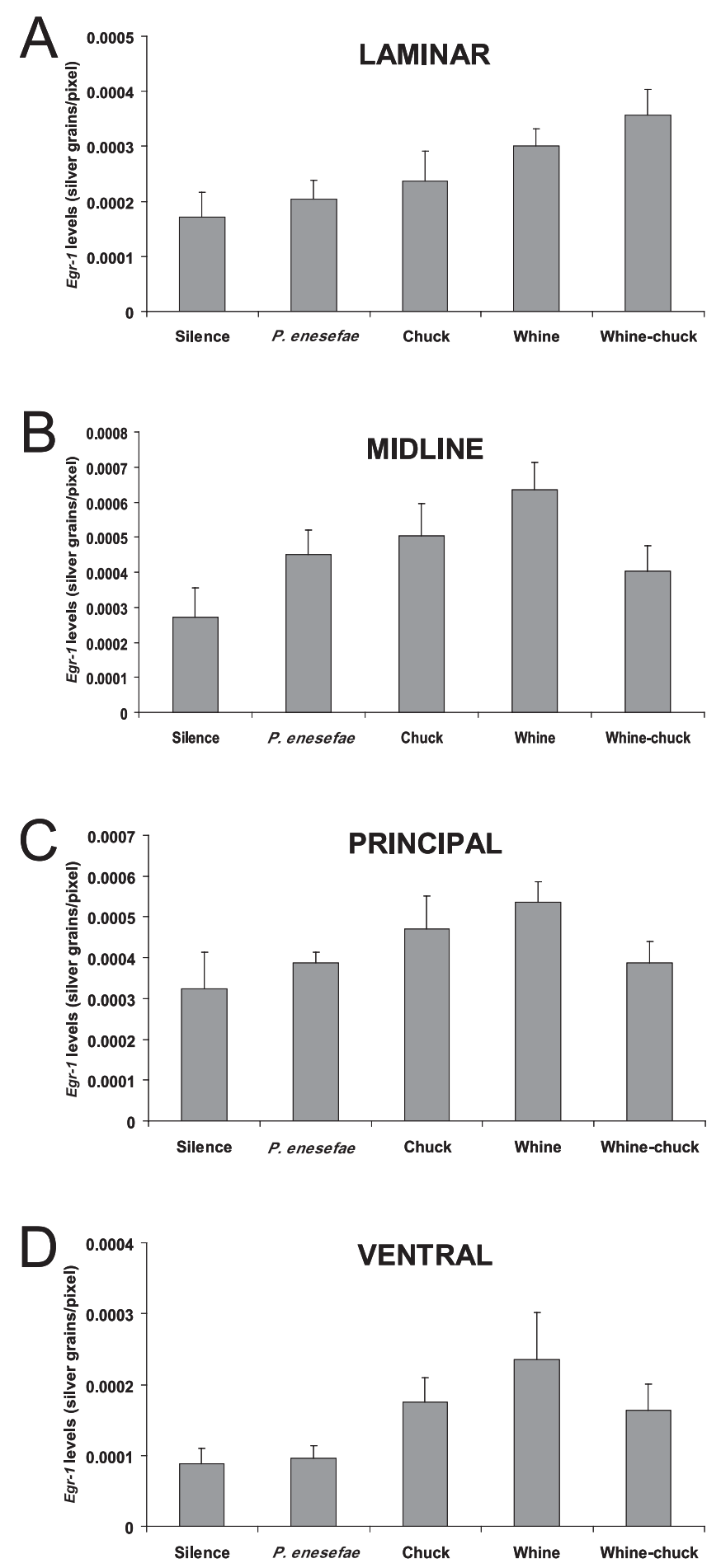

Figure 4. Effects of biologically relevant acoustic stimulation on egr-1 expression within the four subdivisions of the torus semicircularis. Each panel shows mean egr- 1 levels of all frogs in each of the five stimulus conditions with error bars indicating SE. Note $y$-axis scales differ on each graph. A, Egr-1 expression in the laminar nucleus increases in response to sound. Natural conspecific mating calls (whine and whine-chuck) show greater induction than other mating call stimuli (heterospecific whine and chuck only). B, Egr-1 levels in the midline region of animals that heard whines are significantly higher than those in animals exposed to whine-chucks. $C$, In the principal nucleus, egr-1 levels in animals that heard whines are higher than levels in animals presented with whine-chucks. $D$, The ventral region did not show significant egr-1 elevation based on acoustic stimulation. S, Silence; C, chuck; E, P. enesefae whine; W, P. pustulosus whine; WC, P. pustulosus whine-chuck. laminar region differed from that of the midline and principal regions, which had elevated egr-1 levels for only one conspecific call, suggesting different roles in call discrimination. Furthermore, analyzing activity patterns across all four toral subdivisions better distinguished among mating call stimuli than did considering activity within only one nucleus.

\section{Functional heterogeneity of auditory processing of complex biological signals}

The pattern of egr-1 expression in the torus semicircularis revealed a functional heterogeneity of auditory processing of complex signals. Egr-1 expression in the laminar subdivision responded preferentially to conspecific mating calls (whines and whine-chucks), whereas the midline and principal subdivisions showed a bias toward the whine. These different response patterns suggest that toral regions are tuned to different aspects of biological signals. Although several previous electrophysiological studies compared neuronal responses to natural calls, they did not distinguish neurons based on toral subdivision (Diekamp and Schneider, 1988; Fuzessery, 1988; Penna et al., 1997), making it difficult to compare with our egr-1 data. Given that egr-1 expression and action potentials are often initiated by activation of the same neurotransmitter systems (for review, see Clayton, 2000; Jarvis 2004), the two responses are intrinsically linked and often yield similar results (Mello and Clayton, 1994; Jarvis and Nottebohm, 1997; Clayton, 2000; Stripling et al., 2001; Jarvis, 2004). However, the relationship between electrical activity and egr-1 expression is complex because egr-1 induction relies on the particular contingent of activators and repressors present in the cell, a contingent that may vary spatially with cell type and temporally with context (Jarvis, 2004). In assigning functional roles to toral regions, we consider egr-1 levels as indicators of presynaptic neurotransmitter release in response to acoustic stimulation.

Egr-1 expression in the laminar nucleus responded to mating calls in accordance with their biological salience. The laminar nucleus showed progressively higher egr-1 expression from no sound to nonsalient signals (heterospecific calls and chucks) to conspecific calls that normally elicit vigorous behavioral responses (whines and whine-chucks). The laminar nucleus distinguished best between conspecific and nonsalient mating calls. Because the heterospecific $P$. enesefae whine contained the most acoustic energy of all stimuli used but showed lower egr-1 levels, laminar nucleus activity is not simply correlated with the total acoustic stimulation of the periphery. In addition to its auditory input, the laminar nucleus receives modulatory input that is heavily dominated by forebrain limbic areas, such as the preoptic area and hypothalamus (Endepols and Walkowiak, 1999). Furthermore, steroid binding sites are present in this toral subdivision (Kelley et al., 1975; Morrell et al., 1975; Endepols et al., 2000). In light of this limbic and endocrine modulation, we propose that egr-1 responses of laminar nucleus neurons may be influenced by the biological meaning of signals. The increased response to behaviorally relevant calls in the laminar region is also consistent with a postulated role in coordinating behavioral responses to sound (Endepols and Walkowiak, 1999). We note, however, that producing calls did not significantly alter laminar nucleus egr-1 levels. Either laminar nucleus inputs are not activated during call production or motor-related inputs do not induce egr-1 expression as do auditory inputs. These egr-1 results suggest that the laminar nucleus may be more invested in processing stimuli relevant to behavioral responses rather than generating those motor responses per se.

The pattern of egr-1 expression was similar in the principal 
Table 3. Orthogonal contrasts characterizing effects of stimulus on egr-1 expression in toral subdivisions

\begin{tabular}{|c|c|c|c|c|c|c|c|c|c|}
\hline \multirow[b]{2}{*}{ Contrast } & \multirow{2}{*}{$\begin{array}{l}\text { Contrast code } \\
S, E, C, W, W C\end{array}$} & \multicolumn{2}{|c|}{ Laminar $(\mathrm{df}=40)$} & \multicolumn{2}{|c|}{ Midline $(\mathrm{df}=39)$} & \multicolumn{2}{|c|}{ Principal $(\mathrm{df}=40)$} & \multicolumn{2}{|c|}{ Ventral $(\mathrm{df}=40)$} \\
\hline & & $t$ & $p$ & $t$ & $p$ & $t$ & $p$ & $t$ & $p$ \\
\hline Sound versus no sound & $-4,1,1,1,1$ & 1.827 & 0.076 & 1.443 & 0.158 & 0.477 & 0.636 & 1.653 & 0.107 \\
\hline Salient versus nonsalient & $0,-1,-1,1,1$ & 2.645 & 0.012 & 0.843 & 0.405 & 1.181 & 0.245 & 0.617 & 0.541 \\
\hline Whine versus whine-chuck & $0,0,0,-1,1$ & 0.449 & 0.656 & 2.432 & 0.020 & 2.053 & 0.047 & 0.967 & 0.340 \\
\hline
\end{tabular}

For each brain regions, the first column indicates the test statistic $t$, and the second contains the associated $p$ value with degrees of freedom (df) listed in column headers. Abbreviations for stimuli as in Figure 4 legend.

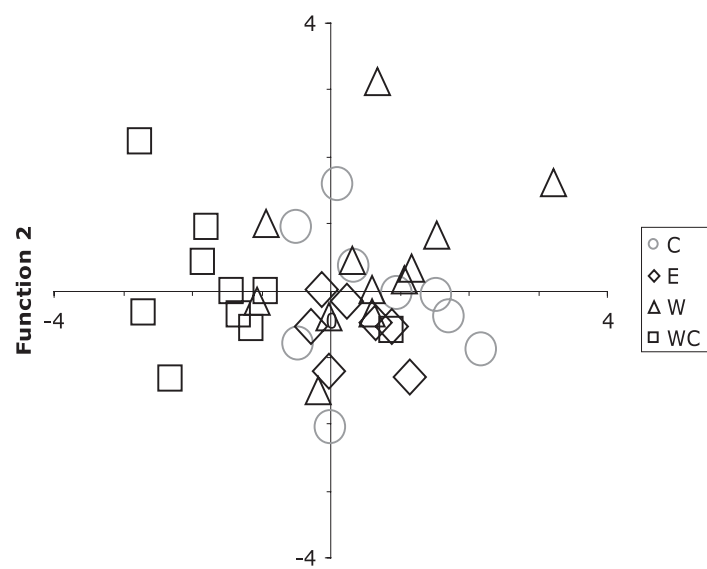

Function 1

Figure 5. Discriminant function analysis classifies individuals based on acoustic stimulus using mean egr-1 expression values for all four toral subdivisions. Classification was based on three functions, the primary two shown here on the horizontal (function 1) and vertical (function 2) axes. Egr-1 expression of each individual is represented by a symbol positioned at the calculated values for function 1 and function 2. Symbol shape indicates which acoustic stimulus the individual heard (key on the right of the figure; abbreviations as in Fig. 4). The degree of clustering of each symbol shows how well animals presented with that stimulus were classified based on egr-1 expression patterns.

Table 4. Discriminant function classification of acoustic stimuli using egr-1 expression levels in four toral subdivisions

\begin{tabular}{|c|c|c|c|c|c|c|}
\hline \multirow{2}{*}{$\begin{array}{l}\text { Stimulus } \\
\text { presented }\end{array}$} & \multirow{2}{*}{$\begin{array}{l}\text { Sample } \\
\text { size }\end{array}$} & \multicolumn{4}{|c|}{ Discriminant classification } & \multirow{2}{*}{$\begin{array}{l}\text { Percentage } \\
\text { classified } \\
\text { correctly }\end{array}$} \\
\hline & & P. enesefae & Chuck & Whine & Whine-chuck & \\
\hline P. enesefae & 7 & 6 & 1 & 0 & 0 & 85.7 \\
\hline Chuck & 9 & 3 & 4 & 2 & 0 & 44.4 \\
\hline Whine & 12 & 2 & 1 & 7 & 2 & 58.3 \\
\hline Whine-chuck & 10 & 1 & 0 & 0 & 9 & 90.0 \\
\hline
\end{tabular}

Table 5. Standardized canonical discriminant coefficients for each discriminant function with eigenvalues and percentage of variance explained for each function in parentheses

\begin{tabular}{lclc}
\hline & $\begin{array}{l}\text { Function 1 } \\
(0.991,85 \%)\end{array}$ & $\begin{array}{l}\text { Function 2 } \\
(0.149,13 \%)\end{array}$ & $\begin{array}{l}\text { Function 3 } \\
(0.018,1.5 \%)\end{array}$ \\
\hline Laminar & -1.590 & 0.348 & 0.151 \\
Midline & 0.985 & 0.197 & 1.408 \\
Principal & 0.632 & 0.103 & -1.298 \\
Ventral & 0.086 & 0.624 & -0.148 \\
\hline
\end{tabular}

and midline nuclei. The correlation in expression was highest between these nuclei compared with any other pairwise relationship, and the pattern of change with stimuli is different from that seen for the laminar nucleus. Potter (1965) reported no auditory responses in one penetration through midline divisions, and subsequent electrophysiological investigations have not attempted to clarify the roles of midline cells. More extensive probing, as recommended by Potter (1965), may reveal midline auditory re- sponses using electrophysiology, or perhaps midline neurons do not respond to simple stimuli that have generally been used to mark the boundaries of acoustically sensitive regions. Nevertheless, the similarity in egr-1 induction patterns between the principal and midline regions suggests that we should consider the relatively little understood midline region as functionally related to the principal rather than the laminar nucleus. The midline and principal nuclei showed strongest distinction between whine and whine-chuck. Unexpectedly, this was caused by lower responses to the whine-chuck, which is the behaviorally preferred and more acoustically complex call. To determine which features activate the principal and midline regions would require both a more resolved description of the timing of egr-1 induction as well as a parametric analysis of egr- 1 and electrophysiological responses to different acoustic stimuli.

We distinguished a ventral toral region beneath the cell dense portion of the principal nucleus on cytoarchitectonic grounds because of its reduced cell density, as also seen in ranid frogs (Wilczynski, 1988). The egr-1 results suggest that it is functionally different as well. The ventral region did not show effects of stimulus condition on egr-1 expression, and the standardized canonical discrimination coefficients show only minor contribution to the DFA classification by the ventral region. It may simply be that cells in this region are not sensitive to the particular stimuli we used, or that, unlike in other toral regions, acoustic stimulation does not trigger changes in egr-1 expression here. In addition, acoustic responses have been described for only magnocellular neurons, a subpopulation of our ventral area that we could not distinguish based on landmarks. Hence, egr-1 induction confined to magnocellular neurons may have been masked by unresponsive smaller neurons and glia in the ventral region. At present, all we can conclude is that the coding of mating calls is not reflected in changes in mean levels of egr-1 expression in this part of the midbrain.

\section{Parallel processing of complex acoustic stimuli}

Using egr-1 expression to study nervous system responses to complex stimuli enabled us to examine the contribution of the four toral subdivisions simultaneously to ask whether the pattern of activity across toral subdivisions better represented call variation than did differences in any one nucleus. Analysis of egr-1 levels across subdivisions using DFA correctly identified $\sim 70 \%$ of the calls, significantly better than DFA, including egr- 1 expression of only a single toral region. Thus, the four midbrain divisions together contain more information about signal variation than do activity differences within any one nucleus, and more accurately map onto known behavioral discrimination between mating calls.

Because a toral target integrating a linear combination of inputs from multiple toral subdivisions could distinguish among all four mating calls by DFA, we propose that multiple toral regions, with their separate response patterns, may generate behavioral biases to mating calls. Toral regions may engage in parallel processing of different aspects of mating calls, either spectral and 
temporal aspects (Diekamp and Schneider, 1988; Fuzessery, 1988; Walkowiak, 1988; Feng at el., 1990; Walkowiak and Luksch, 1994; Penna et al., 1997; Edwards et al., 2002) or other distinct specializations. Alternatively, one toral region may provide all acoustic processing used for mating decisions, but the distinct functions of the other regions (e.g., sound localization) yield egr-1 response patterns conducive to statistical, but not behavioral, stimulus discrimination. In this latter case, forebrain targets of the toral region responsible for call processing may have significant egr-1 biases both for conspecific calls and for whinechucks over whines, although no midbrain region showed such biases, as has been shown in a songbird (Sockman et al., 2002). Further experiments are required to determine whether the auditory midbrain regions have different analytic or integrative functions, and how these roles relate to thalamic specializations (Hall and Feng, 1987) and mating call detection in other brain regions.

In conclusion, the analysis of egr-1 expression in the torus semicircularis enabled us to visualize a snapshot of neural activation after stimulation by biologically relevant sounds. Our results suggest some heretofore hidden processing specializations. Laminar nucleus egr-1 responses may be related to the biological meaning of acoustic signals, that is, their differential ability to trigger natural behavioral responses, rather than simple acoustic properties. Egr-1 activity in the midline and principal nuclei shows a different specificity than seen in the laminar nucleus. Discriminant function analyses showed that the overall egr-1 pattern across toral nuclei is a more reliable discriminator of stimuli than is any one nucleus, intimating that this functional heterogeneity could contribute to mating call processing. In addition to providing insights into the coding of acoustic communication signals in this brain area, the present results provide a foundation for more complete analyses of the neural contributions to the complex sensory, motor, and physiological components of social behavior and the way in which communication signals are represented by changes in interconnected networks of brain areas.

\section{References}

Bozon B, Kelly A, Josselyn SA, Silva AJ, Davis S, Laroche S (2003) MAPK, CREB and zif268 are all required for the consolidation of recognition memory. Philos Trans R Soc Lond B Biol Sci 358:805-814.

Buchwalter G, Gross C, Wasylyk B (2004) Ets ternary complex transcription factors. Gene 324:1-14.

Burmeister SS, Fernald RD (2005) Evolutionary conservation of the egr-1 immediate-early gene response in a teleost. J Comp Neurol 481:220-232.

Cheng HY, Clayton DF (2004) Activation and habituation of extracellular signal-regulated kinase phosphorylation in zebra finch auditory forebrain during song presentation. J Neurosci 24:7503-7513.

Clayton DF (2000) The genomic action potential. Neurobiol Learning and Memory 74:185-216.

Diekamp B, Schneider H (1988) Neuronal processing of conspecific and related calls in the torus semicircularis of Rana r. ridibunda Pall. (Anura): single-unit recordings. J Comp Physiol [A] 163:301-315.

Edwards CJ, Alter TB, Rose GJ (2002) Auditory midbrain neurons that count. Nat Neurosci 5:934-936.

Endepols H, Walkowiak W (1999) Influence of descending forebrain projections on processing of acoustic signals and audiomotor integration in the anuran midbrain. Eur J Morphol 37:182-184.

Endepols H, Walkowiak W (2001) Integration of ascending and descending inputs in the auditory midbrain of anurans. J Comp Physiol [A] 186:1119-1133.

Endepols H, Walkowiak W, Luksch H (2000) Chemoarchitecture of the anuran auditory midbrain. Brain Res Rev 33:179-198.

Endepols H, Feng AS, Gerhardt HC, Schul J, Walkowiak W (2003) Roles of the auditory midbrain and thalamus in selective phonotaxis in female gray treefrogs (Hyla versicolor). Behav Brain Res 145:63-77.
Feng AS (1983) Morphology of neurons in the torus semicircularis of the northern leopard frog, Rana pipiens pipiens. J Morphol 175:253-269.

Feng AS (1986a) Afferent and efferent innervation patterns of the cochlear nucleus (dorsal medullary nucleus) of the leopard frog. Brain Res 367:183-191.

Feng AS (1986b) Afferent and efferent innervation patterns of the superior olivary nucleus of the leopard frog. Brain Res 364:167-171.

Feng AS, Lin WY (1991) Differential innervation patterns of three divisions of frog auditory midbrain (torus semicircularis). J Comp Neurol 306:613-630.

Feng AS, Hall JC, Gooler DM (1990) Neural basis of sound pattern recognition in anurans. Prog Neurobiol 34:313-329.

Fuzessery ZM (1988) Frequency tuning in the anuran central auditory system. In: The evolution of the amphibian auditory system (Fritzsch B, Ryan MJ, Wilczynski W, Hetherington TE, Walkowiak W, eds) pp 253273. New York: Wiley.

Gentner TQ, Hulse SH, Duffy D, Ball GF (2001) Response biases in auditory forebrain regions of female songbirds following exposure to sexually relevant variation in male song. J Neurobiol 46:48-58.

Hall JC, Feng AS (1987) Evidence for parallel processing in the frog's auditory thalamus. J Comp Neurol 258:407-419.

Harada T, Morooka T, Ogawa S, Nishida E (2001) ERK induces p35, a neuron-specific activator of Cdk5, through induction of Egr1. Nat Cell Biol 3:453-459.

Jarvis ED (2004) Brains and birdsong. In: Nature's music: the science of birdsong (Marler P, Slabberkoorn H, eds), pp 239-275. New York: Elsevier-Academic.

Jarvis ED, Nottebohm F (1997) Motor-driven gene expression. Proc Natl Acad Sci USA 94:4097-4102.

Jarvis ED, Ribeiro S, da Silva ML, Ventura D, Vielliard J, Mello CV (2000) Behaviourally driven gene expression reveals song nuclei in hummingbird brain. Nature 406:628-632.

Kelley DB, Morrell JI, Pfaff DW (1975) Autoradiographic localization of hormone-concentrating cells in the brain of an amphibian, Xenopus laevis. I. Testosterone. J Comp Neurol 164:47-59.

Luksch H, Walkowiak W (1998) Morphology and axonal projection patterns of auditory neurons in the midbrain of the painted frog, Discoglossus pictus. Hear Res 122:1-17.

Marin O, Gonzalez A, Smeets WJ (1997) Basal ganglia organization in amphibians: efferent connections of the striatum and the nucleus accumbens. J Comp Neurol 380:23-50.

Maney DL, MacDougall-Shackleton EA, MacDougall-Shackleton SA, Ball GF, Hahn TP (2003) Immediate early gene response to hearing song correlates with receptive behavior and depends on dialect in a female songbird. J Comp Physiol [A] 189:667-674.

Mello CV, Clayton DF (1994) Song-induced ZENK gene expression in auditory pathways of songbird brain and its relation to the song control system. J Neurosci 14:6652-6666.

Mello CV, Ribeiro S (1998) ZENK protein regulation by song in the brain of songbirds. J Comp Neurol 393:426-438.

Mello CV, Vicario DS, Clayton DF (1992) Song presentation induces gene expression in the songbird forebrain. Proc Natl Acad Sci USA 89:6818-6822.

Morrell JI, Kelley DB, Pfaff DW (1975) Autoradiographic localization of hormone-concentrating cells in the brain of an amphibian, Xenopus laevis. II. Estradiol. J Comp Neurol 164:63-77.

Murphy TH, Worley PF, Baraban JM (1991) L-type voltage-sensitive calcium channels mediate synaptic activation of immediate early genes. Neuron 7:625-635.

Penna M, Lin WY, Feng AS (1997) Temporal selectivity for complex signals by single neurons in the torus semicircularis of Pleurodema thaul (Amphibia: Leptodactylae). J Comp Physiol [A] 180:313-328.

Potter HD (1965) Mesencephalic auditory region of the bullfrog. J Neurophysiol 28:1132-1154.

Rand AS, Ryan MJ (1981) The adaptive significance of a complex vocal repertoire in a neotropical frog Physalaemus pustulosus. Zeitschrift fur Tierpsychologie 57:209-214.

Rose GJ, Capranica RR (1984) Processing amplitude-modulated sounds by the auditory midbrain of two species of toads: matched temporal filters. J Comp Physiol [A] 154:211-219.

Rubinson K, Skiles MP (1975) Efferent projections of the superior olivary nucleus in the frog Rana catesbeiana. Brain Behav Evol 12:151-160. 
Ryan MJ (1985) The túngara frog: a study in sexual selection and communication. Chicago: University of Chicago.

Ryan MJ, Rand AS (1990) The sensory basis of sexual selection for complex calls in the túngara frog, Physalaemus pustulosus. Evolution 44:305-314.

Ryan MJ, Rand AS (1993) Species recognition and sexual selection as a unitary problem in animal communication. Evolution 47:647-657.

Ryan MJ, Rand AS (1998) Evoked vocal response in male túngara frogs: Preexisting biases in male responses? Anim Behav 56:1509-1516.

Sockman KW, Gentner TG, Ball GF (2002) Recent experience modulates forebrain gene-expression in response to mate choice cues in European starlings. Philos Trans R Soc Lond B Biol Sci 269:2479-2485.

Stripling R, Kruse AA, Clayton DF (2001) Development of song responses in the zebra finch caudomedial striatum: role of genomic and electrophysiological activities. J Neurobiol 48:163-180.

Sweatt JD (2001) The neuronal MAP kinase cascade: a biochemical signal integration system subserving synaptic plasticity and memory. J Neurochem 76:1-10.

Tabachnick B, Fidell G (1983) Using multivariate statistics. New York: Harper and Row.

Treisman R (1996) Regulation of transcription by MAP kinase cascades. Curr Opin Cell Biol 8:205-215.

Walkowiak W (1984) Neural correlates of the recognition of pulsed sound signals in the grass frog. J Comp Physiol [A] 138:131-148.
Walkowiak W (1988) Neuroethology of anuran call recognition. In: The evolution of the amphibian auditory system (Fritzsch B, Ryan MJ, Wilczynski W, Hetherington TE, Walkowiak W, eds), pp 209-231. New York: Wiley.

Walkowiak W, Luksch H (1994) Sensory motor interfacing in acoustic behavior of anurans. Am Zool 34:685-695.

Whitmarsh AJ, Shore P, Sharrocks AD, Davis RJ (1995) Integration of MAP kinase signal transduction pathways at the serum response element. Science 269:403-407.

Wilczynski W (1981) Afferents to the midbrain auditory center in the bullfrog Rana catesbeiana. J Comp Neurol 198:421-433.

Wilczynski W (1988) Brainstem auditory pathways in anuran amphibians. In: The evolution of the amphibian auditory system (Fritzsch B, Ryan MJ, Wilczynski W, Hetherington TE, Walkowiak W, eds), pp 209-231. New York: Wiley.

Wilczynski W, Capranica RR (1984) The auditory system of anuran amphibians. Prog Neurobiol 22:1-38.

Wilczynski W, Northcutt RG (1983) Connections of the bullfrog striatum: efferent projections. J Comp Neurol 214:333-343.

Worley PF, Christy BA, Nakabeppu Y, Bhat RV, Cole AJ, Baraban JM (1991) Constitutive expression of zif268 in neocortex is regulated by synaptic activity. Proc Natl Acad Sci USA 88:5106-5110. 